\title{
Uma falsa lição de anatomia ou de um simples caso de impregnação teórica dos fatos
}

\author{
Eduardo Henrique Peiruque Kigkhöfel
}

\section{A arte secreta de Michelangelo. Uma lição de anatomia na Capela Sistina \\ Gilson Barreto e Marcelo G. de Oliveira \\ Editora ARX}

São Paulo, 2004, 230 págs.

Dado o grau de complexidade e a quantidade hoje disponível de conhecimentos acadêmicos, para o bem e para o mal, as formações especializadas fazem parte do cotidiano universitário. Estuda-se meticulosamente assuntos muito específicos na expectativa da realização de um trabalho original. $\mathrm{O}$ mundo acadêmico é pródigo de exemplos de que uma formação especializada não garante uma contribuição original em uma área específica, mas sua importância não pode ser subestimada. Após uma idéia que se apresenta inicialmente dessa forma, uma formação é importante e mesmo necessária para que uma idéia seja desenvolvida e fundamentada. Trata-se de proporcionar à investigação contornos objetivos, no sentido de que seus resultados e conclusões possam ser avaliados por outros estudiosos.

O livro recentemente lançado $A$ arte secreta de Michelangelo, de autoria do médico Gilson Barreto e do químico Marcelo G. de Oliveira, apresenta uma tese inovadora e ousada: imbuído de estudos sistemáticos de anatomia tal qual muitos médicos anatomistas de sua época, Michelangelo pintou estruturas anatômicas camufladas em muitas figuras da Capela Sistina, de modo a fornecer uma lição de anatomia um tanto original apenas agora decifrada por ambos pesquisadores. ${ }^{1}$ Entretanto, sem formação na área em que se propuseram a trabalhar, essa tese não resiste a um exame crítico.

1 Limito-me aqui à análise das interpretações a respeito da Capela Sistina, mas a crítica aqui feita também é pertinente para as duas esculturas de Michelangelo analisadas no livro em questão. 
Além disso, como premissa de sua argumentação existe a idéia da união efetiva entre as artes e a ciência no Renascimento italiano, idéia que também não resiste a um exame crítico.

Em um texto que freqüentemente aponta para a falta de familiaridade com a cultura e o estilo do período em questão, ${ }^{2}$ as menções aos estudos de anatomia de Michelangelo, enfatizadas pelos autores, são necessárias para seu argumento, mas não são suficientes para sustentá-lo. Não há o menor indício das interpretações propostas em seus desenhos para os afrescos da Capela Sistina (fig. 1 e 2) e nem em seus raros desenhos de anatomia. ${ }^{3}$ Os textos contemporâneos que, de uma forma ou de outra, refletem as pala-

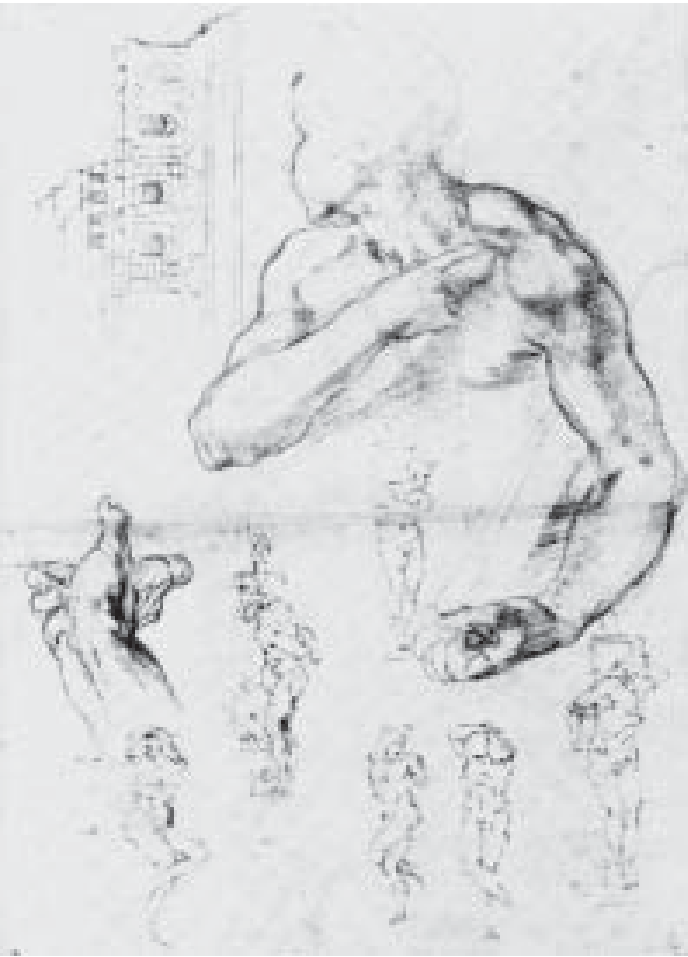

Figura 1. Michelangelo. Estudos de figura para a Capela Sistina e estudo da mão da Sibila Líbica (sangüínea); estudos de escravos para a tumba de Júlio II (pena e nanquim). Oxford, Ashmolean Museum. vras de Michelangelo, como as biografias de Ascanio Condivi (publicada em 1553) e Giorgio Vasari (publicada em 1550, revisada em 1568), também não sugerem isso. Além do mais, não há uma caracterização do período em questão que sustente as interpretações propostas, no sentido de uma aproximação da cultura do Renascimento a partir de seus documentos, como textos e desenhos de artistas contemporâneos de Michelangelo.

2 Por exemplo, os autores (p. 37) interpretam literalmente um texto de Leonardo da Vinci a respeito das diferenças entre o escultor e o pintor, um texto que é evidentemente de feição retórica.

3 Os estudos para a Capela Sistina estão catalogados sob os números 119-174 do catálogo de Tonlay (1975). Os desenhos anatômicos de Michelangelo estão sob os números 105-116 do mesmo catálogo e compreendem um conjunto muito heterogêneo de desenhos espalhado em coleções do Ashmolean Museum (Oxford), da Casa Buonarroti (Florença), do Louvre (Paris), do Teyler Museum (Haarlem), da Royal Library (Windsor) e da Stanza del Borgo (Milão). Com exceção do no. 110, considerado uma cópia, todos esses desenhos estão citados como originais de Michelangelo e suas datações oscilam entre ca. 1505-06 e ca. 1530, mas Tonlay não fornece justificativas para suas datações. Perrig (1991, p. 67), um revisionista radical e irreverente, em um livro brilhante a respeito de atribuição de desenhos de Michelangelo, considera todos os desenhos de anatomia de Michelangelo como cópias. 
Numa tentativa de contornar essa falta, os autores usam as chamadas "pistas", com as quais eles pensam ser possível decifrar os estudos anatômicos camuflados. Por exemplo, segundo os autores (p. 94), a árvore seca que está à esquerda da cena do Dilúvio representa uma ramificação brônquica, sendo a "pista" para essa interpretação a atitude de várias figuras "que repousam as mãos sobre o tórax" e assim chamam "a atenção para essa parte do corpo". Baxandall (1991), em um livro exemplar a respeito de como interpretar pinturas da Itália do século xv, faz uma contextualização dos gestos da época a partir de textos e gravuras e, a partir disso, propõe interpretações de algumas pinturas. Dor, por exemplo, era representada ao se pressionar o peito com a palma da mão, e vergonha, ao se cobrir

Figura 2. Michelangelo. Estudos para a Sibila Líbica (sangüínea). Nova Iorque, Metropolitan Museum. os olhos com os dedos. A partir disso,

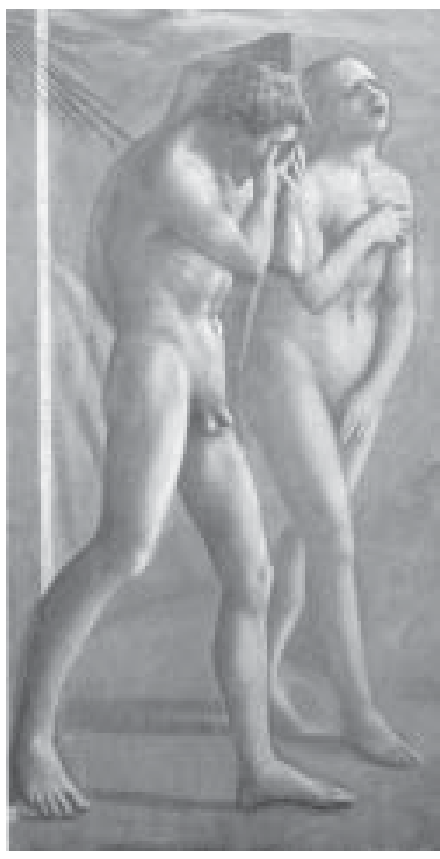

é possível interpretar o afresco $A$ expulsão do Paraíso, de Masaccio, de forma plausível (fig. 3): Adão, com os olhos cobertos, exprime vergonha, e Eva, com suas mãos sobre o peito, apenas dor. Baxandall cita outro gesto em uso na ordem dos Beneditinos que diz respeito ao exemplo do Dilúvio citado acima: "Demonstração: indica-se uma coisa que se viu abrindo a palma da mão em sua direção" (Baxandall, 1991, p. 24, O). Esse gesto, presente em diversas pinturas do século xv, não é a "pista" sugerida acima. Usando palavras de Baxandall, uma investigação nesses termos está relacionada a encontrar o estilo cognitivo de uma época. De fato, os autores evitam uma contextualização histórica, a qual eles pensam ser posterior às suas

Figura 3. Masaccio. A expulsão do Paraíso (afresco).

Capella Brancacci, Santa Maria del Carmine, Florença. 
interpretações. Após sugerirem a existência de um "código secreto", eles escrevem (p. 27) que "suas possíveis implicações históricas e filosóficas estão além de nossa capacidade de análise, que se limitará à descrição da anatomia na arte". Assim, o "código decifrado" (p. 70-1) é apenas uma lista de indicações a respeito de como observar as interpretações arbitrárias e sem fundamento dos próprios autores uma a uma, mas não uma estrutura de sentidos consistente que permita interpretar as formas anatômicas relacionadas entre si e dentro do programa iconográfico da Capela Sistina, o que configuraria uma lição de anatomia, conforme proposto não apenas no título do livro e diversas vezes ao longo de seu texto, mas enfatizado quando os autores mencionam a existência de um "código didático" (p. 214). Tanto quanto os documentos de época permitem supor, não havia um código de época que possibilitava um artista a pintar afrescos conforme os autores sugerem. Eles, a seu modo, admitem isso ao escrever que apenas agora o código (p. 27) "foi quebrado". Por isso, pode-se supor que tal código existiu secretamente na mente do divino Michelangelo e que, por algum motivo não cognoscível a comuns mortais, surgiu de súbito no cérebro de alguns raros escolhidos. Talvez, mas sendo as formas anatômicas tridimensionais, muitas, de acordo com o ângulo de que são vistas, servem tanto às interpretações dos autores quanto a muitas outras, de acordo com a boa vontade e a criatividade de quem as observa, as quais em alguns casos têm de ser extraordinariamente fortes, como para ver, no afresco que narra a história da judia Judite e do general assírio Holofernes, o corpo deste último como uma representação científica da segunda vértebra do pescoço, chamada áxis, com seu processo odontóide em evidência.

Isto posto, não há como pensar por que motivo, em um conjunto de afrescos com um plano nitidamente teológico, Michelangelo representou formas anatômicas. Os autores admitem isso (p. 28), ao escrever que as informações que eles apresentam a respeito de Michelangelo não são suficientes para que se proponha um motivo pelo qual Michelangelo fez o que fez. Entretanto, eles seguem com suas interpretações, restando apenas argumentos historicamente pouco convincentes (p. 216): "Considerando-se a sua extensa experiência em dissecação e seu grande interesse pela anatomia dos órgãos internos, não há razão para que formas anatômicas (além das formas da musculatura externa) não estivessem também presentes no restante de sua arte plástica".

\section{III}

A referência acima à "extensa experiência em dissecação de Michelangelo" e a "seu grande interesse pela anatomia dos órgãos internos" está inteiramente baseada na idéia de uma união entre as artes e a ciência no Renascimento, um topos entre os historiado- 
res da arte, premissa de toda a argumentação do livro em questão. Os autores destacam isso de diversas formas. Por exemplo, comentando a obra de Andreas Vesalius (p. 48), eles mencionam "aquele encontro histórico entre arte e ciência”, e enfatizam isso pouco após (p. 7o), ao mencionar que Michelangelo, "no coração da Igreja, imortalizou a comunhão da arte com o conhecimento científico". Entretanto, eles não fornecem definições mínimas de seus termos centrais a partir de textos de época, de modo que seus argumentos também são desprovidos de sentido histórico objetivo.

O termo "arte" no Renascimento esteve ligado à definição de Aristóteles, qual seja, produzir a partir de princípios, mas não necessariamente os primeiros. De forma sucinta, Aristóteles diz na Ética a Nicômaco (VI, 1140a 20-22) que arte é "uma disposição que se ocupa de produzir, envolvendo o reto raciocínio”. 4 Em outras palavras, o termo arte significava manualidade ou a habilidade voltada a realizar algo material. Um memorando do representante do duque de Milão em Florença, escrito circa 14,90, ilustra esse conceito de forma clara: "Filippino, filho do grande pintor Fra Filippo Lippi: aluno do acima mencionado Botticelli e filho do mais ilustre pintor de seu tempo. Suas coisas têm um ar mais doce que as de Botticelli; não creio que tenha[m] tanta arte" (Baxandall, 1991, p. 33; grifo no original). Também derivado do sentido aristotélico, o termo "ciência" no Renascimento, por sua vez, definiu o resultado abstrato da operação de separação entre o que em um determinado conjunto de experiências era comum e o que fazia parte do variável, sendo o que era variável apenas um acidente em relação ao que era comum, sua essência. Publicado em Colônia em 1574, o livro de Franciscus Toletus, Commentaria una cum quaestionibus in VIII libros De physica auscultatione, elucida o sentido desse conceito no período em questão. Para Toletus, as três principais divisões da philosophia foram a speculativa, a practica e a factiva, e destas, a primeira era subdividida em metaphysica, mathematica e physica ou philosophia naturalis. A metaphysica tratava dos princípios mais comuns de todo ser; a mathematica, por sua vez, era subdividida em mathematica pura, que estudava as entidades que não dependiam do movimento e eram abstraídas desse, e a mathematica media, que estudava as entidades abstraídas mas ainda encontradas em movimento; e, por fim, à physica cabia estudar tudo o que dizia respeito aos sentidos (cf. Wallace, 1988, p. 201). Ciência, physica,

4 É importante evitar confundir esse sentido específico do termo "arte" com seu uso relacionado aos estudos teóricos chamados Artes Liberais, compreendidos pelo Trivium (grammatica, logica e rhetorica) e o Quadrivium (arithmetica, geometria, musica e astronomia). Esses termos característicos da escolástica têm sua origem nos sofistas gregos, que lançaram as bases para a elaboração do trivium e do quadrivium ocorrida no final da Antigüidade; a língua grega da época dos sofistas não possuía uma palavra específica para separar a noção de saber e de poder vindos da ação, de modo que a palavra "arte" significava tanto as "artes profissionais" quanto as "artes educativas", estas últimas voltadas à vida política do cidadão ateniense. Sobre isso, cf. Jaeger, 1979, p. 311-57. 
philosophia ou scientia naturalis, a partir da qual foram elaboradas as ciências modernas, era um corpo de conhecimentos organizado segundo princípios definidos, sendo seu objetivo principal o conhecimento das primeiras causas. Nesses termos, a distinção entre os estudiosos da filosofia natural e os $\operatorname{artistas}^{5}$ do período em questão é simples e clara. Um artista utilizava seus Figura 4. Michelangelo. A punição de Tityos (giz negro).Windsor Castle, Royal Library. conhecimentos empíricos-eventualmente formalizados sob a forma de desenhos, mas raramente sob a forma de um discurso sistemático ${ }^{6}$ - para realizar sua arte específica, como a pintura ou a escultura, entre diversas outras (fig. 4). Um filósofo natural formalizava sob a forma de discurso seus conhecimentos teóricos relacionados ao mundo físico. Entre ambos, existiram diferenças de objetivos, métodos e formas de realização de seus respectivos conhecimentos.

Assim, é correto pensar que no século xv houve uma aproximação entre as artes e a filosofia natural. Alguns conhecimentos pertencentes até então ao âmbito da filosofia natural foram aplicados nas atividades até então eminentemente práticas. Por exemplo, o estudo de perspectiva dos artistas do Renascimento foi apenas uma parte de um corpus de conhecimento óptico muito amplo, cujos textos principais eram os de Alhazen, Peckham, Roger Bacon e Pelacano, porção que tinha por objetivo apenas estabelecer corretamente as dimensões dos objetos aos olhos dos homens sobre uma superfície pictórica plana (fig. 5). Antonio di Tuccio Manetti, em sua biografia de Filippo Brunelleschi escrita circa 1480, deixa isso claro:

Aquilo que os pintores atualmente chamam de perspectiva é aquela parte da ciência da perspectiva que se volta praticamente a reduzir ou ampliar sistematicamente, conforme aquilo que o olho percebe, os objetos que estão respectivamente

\footnotetext{
5 Por facilidade de exposição, o termo "artista" nesta resenha está utilizado em seu sentido atual e refere-se a pessoas como Sandro Boticelli, por exemplo, assim como a Michelangelo Buonarrotti.

6 Cita-se, por exemplo, aqui o pequeno tratado de Cennino Cennini di Valdelsa, do início do século xv, o qual é um manual para a prática de ateliê, sem elaborações teóricas sofisticadas. O terceiro Comentário de Lorenzo Ghiberti (1378-1455), escrito por volta de 1447, é um texto voltado a determinar as bases teóricas das artes, mas resta inacabado. Leon Battista Alberti (14,04,-1472), por sua vez, escreveu diversos livros que sistematizam as práticas artísticas da época, como a pintura (De pictura) e a escultura (De statua). Entretanto, Alberti pertenceu a um âmbito de cultura muito diverso dos artistas que trabalhavam em ateliês. A maior parte de sua produção escrita não está destinada às artes, e dele não se conhece obras de pintura e escultura, mas apenas de arquitetura.
} 
afastados ou próximos - que se trata de construções, planícies, montanhas e paisagens de todo tipo - e de figuras e outros objetos em todos os lugares pelo tamanho que parecem ter de uma certa distância, correspondendo ao seu maior ou menor distanciamento (apud Baxandall, 1991, p. 200).

No caso da anatomia, muitos artistas do século xv possivelmente assistiram (e talvez realizaram) dissecções para realizar suas pinturas e esculturas, entre outras obras, e é prudente pensar que eles estudaram muito mais a anatomia da superfície do corpo do que as dissecções anatômicas propriamente ditas, como as feitas nas escolas de medicina, e que eles pouco se interessaram pela relação entre as formas e os usos (no sentido de funções) do corpo humano.

Em Florença, segundo o Statuta universitatis et studiiflorentini de 1387 , os pintores e escultores foram aceitos na Consorteria dei Medici e degli Speziali no

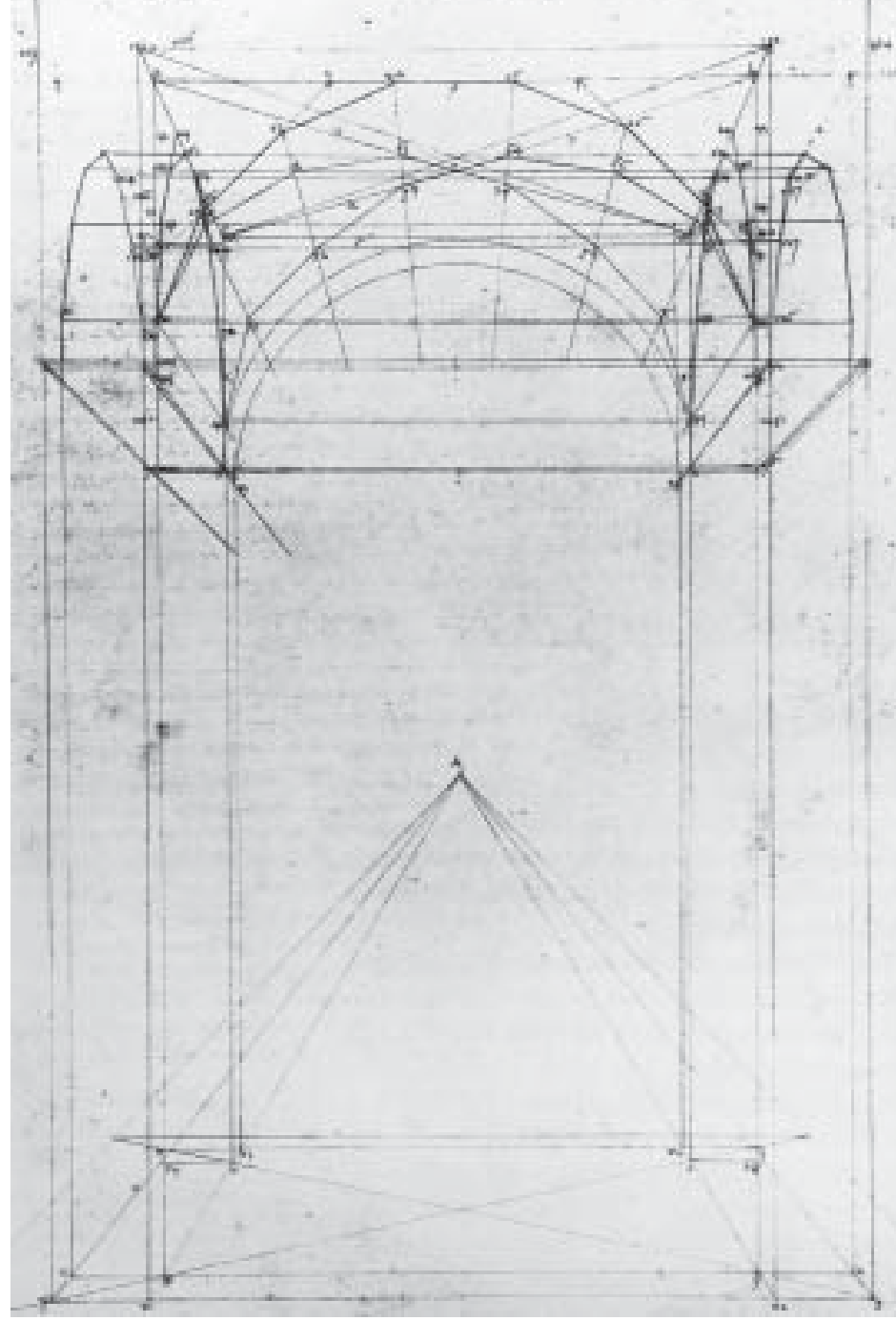

Figura 5. Piero della Francesca. Representação perspectiva do tratado De prospectiva pingendi (pena e nanquim). Bibioteca Palatina, Parma, MS. Parm. ${ }_{1576}$, fol. 29 r. ano de 13 ○3. Conforme o documento, aos artistas eram entregues à vontade corpos de pessoas que morriam de causas naturais no hospital de Santa Maria Novella ou em outras enfermarias da cidade, enquanto aos médicos apenas dois cadáveres de criminosos enforcados de ambos os sexos eram fornecidos por ano (excepcionalmente três, dois homens e uma mulher) para o exercício anatômico. $\mathrm{O}$ motivo desta desigual distribuição foi que enquanto os artistas apenas se preocupavam com a superfície dos cadáveres, os médicos os dissecavam e destruíam todas as suas partes (Statuta universitatis et studii florentini, 6 Rubriche, 62a até 72a. Cf. Bernabeo, 1984, p. 31).

Em conformidade com isso, no sentido de mostrar a diferença de abordagem entre médicos e artistas sobre o corpo humano, segundo o tratado Anothomia de Hieronymo Manfredi, escrito em Bolonha circa 1490, a anatomia superficial ainda era de pouco interesse para os médicos. Apenas os últimos quatro fólios do manuscrito desse 
tratado - a partir do final do fólio $44 \mathrm{r}$ até o fólio $47^{\mathrm{v}}$ - estão dedicados à anatomia das extremidades (cf. Singer, 1975, p. 13o-64). Considerando que o texto de Manfredi, uma ampliação do conhecido texto de Mondino de Luzzi, é um guia de dissecção, pode-se perguntar que conhecimentos um artista podia obter em uma demonstração pública de anatomia para seus fins artísticos. Em suma, não há documentos que sustentem a idéia de que era necessário um artista se familiarizar com a estrutura e os usos do corpo humano para representá-lo em suas obras, excetuando o estranho e singular caso de Leonardo da Vinci, que operou uma aproximação entre as artes e a ciência do período de uma forma inédita e profunda. Leonardo foi o primeiro a sistematizar os conhecimentos técnicos de sua época, de modo a proporcionar à prática uma sistematização teórica elaborada. Uma simples comparação dos manuscritos técnicos de Mariano Taccola e Francesco di Giorgio Martini com os de Leonardo, em especial o Codice Madrid I, evidencia isso. Leonardo também aplicou seus métodos de estudar mecânica (sua "scientia della machine") e máquinas simples a seus estudos de anatomia. Galluzzi (1996) defende essa tese com muita propriedade. Além disso, é importante frisar que a própria disposição de desenhar de Leonardo da Vinci serviu de base para seu modo de elaborar e formalizar suas idéias.

Em poucas palavras, pode-se pensar que as artes foram informadas por conhecimentos da filosofia natural, e se das aplicações desses conhecimentos problemas novos surgiram, esses problemas foram resolvidos em seu próprio âmbito produtivo, pois os artistas que trabalhavam sobre essas aplicações não tinham intenções além de produzir pinturas, esculturas etc., e por esse motivo, suas aplicações permaneceram e permanecem apenas como aplicações.

Nesse sentido, não há meio de sustentar que (p. 32) "na busca pelo ideal de beleza da Antigüidade Clássica, a maioria dos grandes pintores e escultores renascentistas estudou anatomia tanto quanto os médicos", que eles (p. 47) "eram freqüentadores assíduos das demonstrações públicas de dissecção" e que "encontrar um escalpelo no ateliê de um pintor ou escultor era algo natural". Nesse sentido, pergunta-se surpreso a que se refere (p. 47) a "Academia Florentina de Arte", a qual "tomara a atitude inédita de instituir o curso de anatomia em seu currículo". Talvez a referência seja àAccademia del Disegno fundada em 1561 por Giorgio Vasari, mas a parte do texto em que está essa informação é confusa e sugere a existência de uma instituição acadêmica antes da metade do século xvi.

Tampouco há como sustentar o interesse de Michelangelo por anatomia médica. As citações de Condivi presentes no livro em questão apontam para uma direção oposta à proposta por seus autores (p. 51): "[Michelangelo] havia aprendido tanto dessa ciência [dissecção] que pensava em escrever um tratado, como um serviço a quem tivesse interesse em esculpir e pintar os movimentos do corpo e a estrutura dos ossos de 
UMA FALSA LIÇÃo DE ANATOMIA...

todas as maneiras". Seus interesses artísticos também ficam muito claros nas seguintes palavras de Condivi citadas pelos autores (p. 51), que expressam críticas de Michelangelo às teorias artísticas de Albrecht Dürer:

Verdade seja dita, Albrecht aborda apenas as proporções e diversidades do corpo, para as quais nenhuma regra pode ser dada, e apresenta suas figuras de pé, como estacas. Daquilo que é mais importante, os movimentos e gestos do corpo humano, ele não diz uma palavra.

Essa menção, de fato, opõe-se à observação dos autores (p. 4,0) de que "o tema predileto de Michelangelo era a anatomia do homem", uma interpretação feita especialmente para justificar sua tese não fundamentada. Por fim, eles citam Condivi mais uma vez (p. 54-55):

Agora que ele já está com idade avançada e não espera mais revelar suas idéias no mundo da escrita, tem-me revelado tudo nos mínimos detalhes. Também começou a falar a respeito com o mestre Realdo Colombo, um anatomista de primeira linha e amigo pessoal meu e de Michelangelo que, por conta disso, mandou-nos o corpo de um mouro (...). Nesse cadáver, Michelangelo me mostrou coisas raras e escondidas, provavelmente desconhecidas ainda, as quais eu anotei na esperança de um dia poder publicá-las, com a ajuda de um estudioso, para a conveniência e utilização de todos os que desejam lidar com a pintura e a escultura.

Pode-se pensar plausivelmente que Michelangelo não teve formação para escrever um tratado de anatomia médica, como seu planejado trabalho com Realdo Colombo sugere, da mesmo forma que o próprio Condivi que, com sua formação artística, esperava a ajuda de um estudioso para ordenar e publicar suas próprias anotações. Os autores admitem isso ao escrever que (p. 57) "se Michelangelo tivesse realizado o seu [tratado de anatomia], teria existido uma obra que, apesar de concebida para estudantes de arte, certamente haveria ultrapassado as fronteiras dos ateliês para ocupar um lugar de destaque nas bibliotecas de Medicina". Especular sobre a importância de um tratado de anatomia que não existe é um exercício sem sentido para um historiador, e atribuir a uma especulação como essa alguma certeza, um absurdo. Assim, é errôneo chamar Michelangelo (p. 28) de "artista e cientista" e escrever (p. 47) a respeito de sua "formação científica", de suas (p. 50) "investigações científicas" e (p. 57) de seu "conhecimento científico".

$\mathrm{Na}$ mesma linha de raciocínio, considerar Michelangelo humanista é um erro grave (p. 216). O termo humanismo, oriundo de escritores romanos (em especial Cícero 
e Gellius), foi revivido por Francesco Petrarca, Coluccio Salutati e outros durante o século xIV, e por volta da metade do século xv circunscreveu um bem definido ciclo de estudos, os chamados studia humanitatis, o qual incluía a grammatica, a rhetorica, a poetica, a historia e a philosophia moralis. Diferentemente das Artes Liberais do final da Idade Média, o humanismo não incluiu a logica ou o quadrivium (arithmetica, geometria, astronomia e musica), assim como as disciplinas que foram importantes para as universidades durante essa mesma época e o Renascimento, como a teologia, a jurisprudência (direito) e a medicina, e as disciplinas filosóficas que não a ética, como a lógica, a filosofia natural e a metafísica. Entretanto, além de suas especulações filológicas ou filosóficas como literatos, juristas ou filósofos de profissão, muitos estudaram outras disciplinas que se estenderam para além do programa humanista, podendo ser encontrados - a partir de meados do século xv - humanistas que também se exerceram na philosophia naturalis: médicos e professores de medicina, juristas e mesmo teólogos (cf. Kristeller, 1988). Mesmo sendo culto a ponto de ser poeta de reconhecido valor, cujos versos fazem parte de muitas antologias de literatura italiana, Michelangelo evidentemente não se enquadrou nesse âmbito da cultura renascentista.

Além disso, escrever que (p. 45) "os registros de seus estudos influenciaram mais as ciências do que os comentários dos médicos gregos e medievais" e que (p. 216) "a produção artística italiana dos séculos xv e xvi passou a representar um meio de investigação, um instrumento dotado de bases teóricas, que despontou entre as atividade intelectuais mais elaboradas" consiste na consideração do desenvolvimento das ciências naturais modernas principalmente a partir do trabalho dos artistas. Segundo esta perspectiva, arte e ciência estavam (p. 45) "inexoravelmente unidas". Não há como negar seu importante papel no desenvolvimento de ciências naturais como a anatomia, por exemplo. Entretanto, apenas ilustrações não configuram uma ciência, nem mesmo uma ciência descritiva. É errôneo desconsiderar o trabalho de sistematização feito pelos filósofos naturais que estudavam a anatomia do corpo humano e que tinham formação específica para isso, como Andreas Vesalius. Não há documentos que sustentem ambas opiniões. Muito pelo contrário, considerando as habilidades de desenho de Antonio del Pollaiolo e os recursos gráficos então existentes, ilustrações como as do livro de Vesalius podiam ser feitas por volta de 14,80 na Itália, mas isso não ocorreu. De fato, o tratado de Hieronymo Manfredi citado acima, escrito em um ambiente de corte propício às artes, não contém ilustrações, e os livros impressos a respeito de anatomia até meados do século xvi contêm ilustrações evidentemente toscas e muito distantes das habilidades dos artistas da época, como mostra a baixa qualidade das ilustrações anatômicas dos livros de Magnus Hundt, Antropologium, de hominis dignitate natura et proprietalibus (Leipzig, 1501) e Gregorius Reisch, Margarita philosophica (Leipzig, 1503) (fig. 6), e mesmo os textos especificamente voltados para a anatomia 
de Johannes de Kethan, Fasciculus medicinae (Veneza, 1491) e Berengario da Carpi, Carpi anatomia Mundini noviter impressa ac per Carpum castigata, (Bolonha, 1514), Carpi Commentaria cum amplissimus additionibus super anatomia Mundini una cum textu e iusdem in pristinum et verum nitorem redacto (Bolonha, 1521) e Isagogae breves (Bolonha, 1522) (fig. 7).

Assim, não é plausível pensar que os artistas foram responsáveis pelo desenvolvimento da anatomia devido a suas técnicas ilustrativas. Os artistas foram importantes quando trabalharam para os anatomistas das universidades, o que ocorreu principalmente a partir da obra de Andreas Vesalius, De humanis corporis fabrica, feita em solo italiano e publicada na Basiléia em 154.3. Nesse sentido, pensar a produção artística como um "meio" ou "instrumento" implica pensar um fim diferente de um fim artístico, e um fim presumivelmente científico, uma opinião

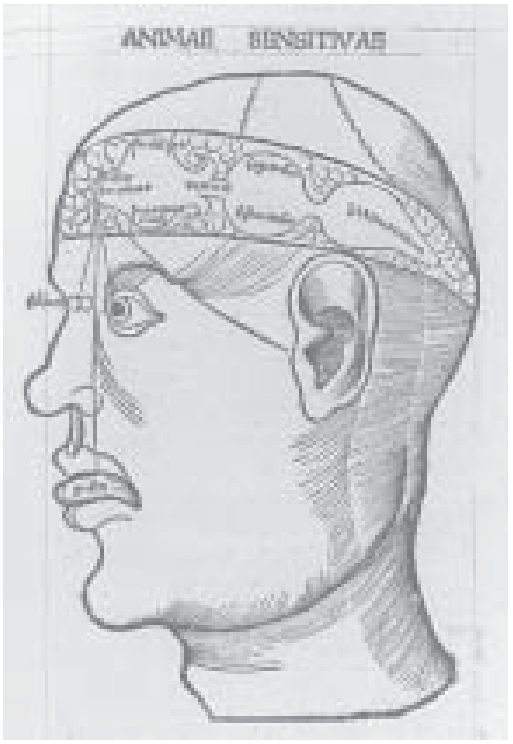

Figura 6. Artista anônimo do norte europeu. Ilustração do livro Margarita philosophica, de Gregorius Reisch (gravura em madeira). muito discutível, conforme exposto acima. Além de

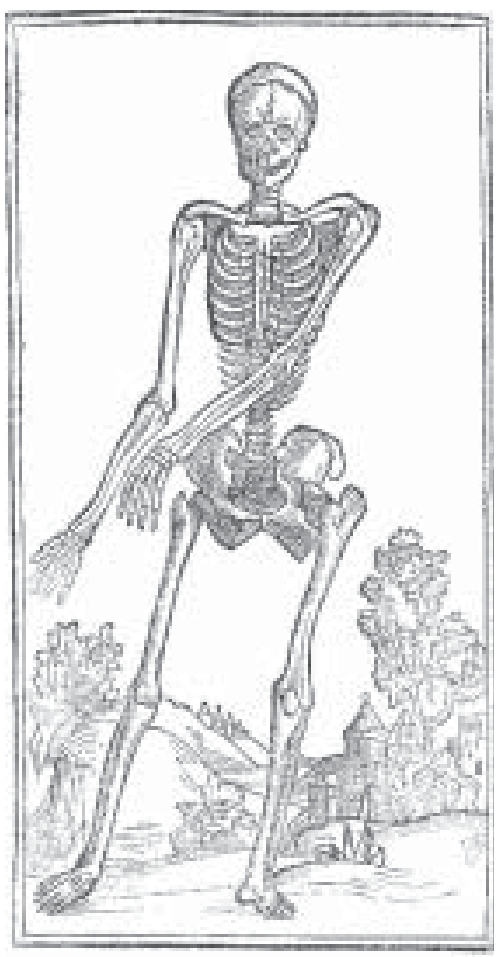

interesses específicos e falta de formação, a inserção de um artista no âmbito da ciência natural era muito restrita. Leonardo da Vinci enfrentou muita resistência ao fazer isso, conforme mostra um texto do Codice Atlantico $11 \mathrm{Zv}^{\mathrm{v}}$ (conforme sua numeração antiga):

Sei bem que por não ser letrado que algum presunçoso poderá razoavelmente me censurar, alegando justamente que eu sou um homem sem letras. Pessoas estúpidas ! [...] Dirão que por não ter eu letras, não posso dizer aquilo de que quero tratar, e não sabem elas que as minhas coisas são mais de serem tiradas da experiência que das palavras de outros, a qual foi mestra de quem bem escreveu, e assim por ser mestra e em todos casos eu a alegarei.

Figura 7. Ugo da Carpi (?). Ilustração do livro Isagogae breves, de Berengario da Carpi (gravura em madeira). 
Sua tentativa de fazer da pintura uma ciência era inviável mesmo em sua época, de modo que Leonardo não deixou uma escola e nem mesmo um único discípulo seguidor de suas idéias muito pouco ortodoxas, como o erudito Paolo Giovio soube já circa 1524 (cf. Giovio apud Barocchi, 1971, p. 7-9). Por fim, se as artes e a ciência estavam "inexoravelmente unidas", aguarda-se ansiosamente uma explicação para o surgimento da ciência matematizada no século xviI.

\section{IV}

Surpreendentemente, opiniões como essas persistem firmes entre historiadores da arte. Entre diversos exemplos, Chastel (1974, p. 219), grande historiador da arte francês, menciona que no século xv os ateliês florentinos foram transformados em "pequenos centros de estudo científico":

Os ateliês haviam se transformado em pequenos centros de estudo científico: a anatomia e a perspectiva não eram ensinadas no Estúdio, mas nos ateliês de Verrocchio e Pollaiuolo. Os conhecimentos empíricos e tecnológicos precisavam ser sistematizados, e um enquadramento conceitual e formas lingüísticas apropriadas era requerido, mas os textos científicos da Antigüidade e mesmo da Idade Média apenas parcialmente proporcionavam isso.

Entretanto, esquecendo o anacronismo de "conhecimentos tecnológicos", os artistas estavam interessados na produção de pinturas, esculturas etc. e tinham métodos específicos para isso, mas não na elaboração sistemática de conceitos e teorias, de modo que a expressão utilizada por Chastel é sem propriedade alguma. Brizio (1974, p. 22-3), vinciana de renome, considerando os artistas florentinos do século xv, escreve:

Ao lado da perspectiva, o outro grande conceito que dominou a arte do Renascimento foi o da imitação da natureza. Isso não deve ser interpretado no sentido restrito do século xix relativo à reprodução externa e epidérmica dos fenômenos da natureza. Para os artistas florentinos dos século xv, a imitação da natureza foi uma 'sutil especulação': eles seguiram a ordem de investigar as leis da natureza e, de acordo com essas mesmas leis, de criar, reproduzindo os processos criativos da própria natureza.

Desconsiderando o anacronismo de "leis da natureza", essa opinião pode ser colocada em questão a partir da simples observação de que não existem escritos de 
artistas - excetuando aqueles a respeito de perspectiva, no sentido exposto brevemente acima - como os de Leonardo da Vinci no século xv ou mesmo xvi. Uma rápida consulta ao grande livro de Schlosser (1994) mostra isso de forma clara. Idéias como essas têm sua origem em um conhecido estudo de Panofsky (1924), segundo o qual artistas como Filippo Brunelleschi e Albrecht Dürer descobriram os princípios da geometria descritiva antes dos matemáticos. Em um ensaio posterior, Panofsky (1962, p. 133) escreve que os esquemas de perspectiva dos artistas renascentistas "colocaram os fundamentos do que foi desenvolvido após como geometria projetiva e analítica" e, defendendo a tese da "descompartimentalização" dos saberes no Renascimento, ele afirma que nesse período (p. 136) "os maiores avanços nas ciências naturais foram feitos por engenheiros, construtores de instrumentos e artistas, mas não os acadêmicos" e que (p. 14,0) "muito do que mais tarde foi isolado como ciência natural veio a existir nos ateliês dos artistas", idéias dure a morire nas mãos de jornalistas e outros escritores diletantes, tanto quanto a de Leonardo da Vinci como gênio incompreendido e antecipador da ciência e de muitas invenções modernas. ${ }^{7}$

Talvez seja interessante especular brevemente a respeito dos motivos da existência de idéias como essas, pois afinal, em um meio de pessoas tão cultas e eruditas, isso tem de ter alguma explicação plausível. Definir arte é uma tarefa notoriamente difícil, talvez porque arte está hoje associada a uma qualidade presente em certos objetos, justamente os objetos de arte, de difícil apreensão discursiva. Entretanto, para os fins aqui propostos, basta pensar que quando se diz hoje "a arte do século xv" pensa-se a respeito das esculturas, pinturas e outras obras do século xv produzidas, ou seja, os produtos de disposições de produzir. Isso é evidente quando se lê um livro cujo título é "História da arte do Renascimento", o qual descreve a história das obras de arte do Renascimento, assim como no título do livro aqui em questão. Arte como uma disposição talvez seja uma noção muito abstrata para o senso comum, especialmente em uma época em que o alto valor monetário de uma obra de arte freqüentemente é notícia de jornal. A ciência que aqui interessa mantém seus contornos gerais desde a época dos gregos, ao menos entre pessoas educadas, no sentido de expressar a busca de relações

\footnotetext{
7 Um exemplo claro disso está em um livro recente de White (2002). Sua "história de reavaliação" da obra de Leonardo da Vinci nada mais é que uma tese muito em voga na primeira metade do século passado, mas que desde então não tem o menor respaldo dos estudiosos vincianos que merecem tal nome. De fato, na introdução de seu livro, sem muita surpresa intitulada "O homem total", White (2002, p. 21) mostra seu desconhecimento grosseiro da historiografia vinciana ao mencionar que "quase nada foi escrito das importantes idéias científicas" de Leonardo da Vinci. Uma breve consulta aos acervos on line da Biblioteca Leonardiana de Vinci <www.reanet.comune.empoli.fi.it/vinci/ home.htm> e do Istituto e museo di storia della scienza de Florença <www.imss.fi.it/biblio/indice.htm> mostra como White, um jornalista inglês de divulgação científica, não sabia minimamente a respeito do assunto que se propôs a escrever.
} 
causais entre os fenômenos do mundo físico. Entretanto, desde o século xvı a ciência está vinculada ao modelo das ciências físico-matemáticas baseadas sobre experimentos e expressões matemáticas, características que ao senso comum configuram conhecimento rigoroso e seguro a ser seguido por todas as disciplinas. Além disso, e eis um ponto importante, desde o século xIX a ciência está fortemente vinculada à tecnologia. Pensa-se assim que qualquer disciplina que faça uso de algum método que se assemelhe minimamente ao chamado "método científico" merece o estatuto de ciência, e que os objetivos das ciências são os produtos tecnológicos delas derivados. Ciência como teoria talvez seja uma noção muito abstrata para o senso comum, principalmente em uma sociedade que se denomina orgulhosamente "sociedade do conhecimento", mas que efetivamente valoriza o lado utilitário e imediatista das ciências, na qual qualquer saber de algum modo científico está voltado à tecnologia e a outras "demandas da sociedade". Isto posto, de modo geral os textos de história da arte do Renascimento não apresentam definições mínimas de "arte" e "ciência" do período e, sem isso, eles aplicam as vagas noções atuais expressas por essas palavras. Assim, pensa-se facilmente que os artistas do Renascimento, investigando anatomia, faziam investigações científicas, e que em suas obras existem conhecimentos científicos, sendo esse efetivamente um de seus objetivos. Segundo esse raciocínio, uma pintura de Piero della Francesca feita nos moldes definidos por Leon Battista Alberti expressa uma concepção de espaço que antecipa o espaço abstrato da ciência do século xvıI, ${ }^{8}$ e uma figura de Antonio del Pollaiolo contém conhecimentos de anatomia médica. Segue-se disso que suas práticas artísticas e suas obras influenciaram as ciências naturais no período. Nesse âmbito repleto de muita beleza e pouca sofisticação conceitual, "arte" e "ciência" são termos tão vagos e mal aplicados a ponto de serem intercambiáveis. No caso do livro em questão, um livro muitíssimo longe da imensa cultura e erudição dos livros de Panofsky, só faltou os autores escreverem $A$ ciência secreta de Michelangelo.

\section{$\mathrm{V}$}

A obra de Michelangelo e sua relação com a cultura da Renascença são evidentemente complexas, como atesta não só a perenidade de sua obra, mas também a imensa fortuna crítica a seu respeito. No caso da Capela Sistina, Michelangelo se dirigiu a um público específico com uma educação específica. Passados quase cinco séculos de sua

8 Seu tratado De prospectiva pingendi (A perspectiva dos pintores), da segunda metade do século xv, tem bases evidentemente euclidianas e é um texto voltado à prática dos pintores, como seu título indica, mas não uma contribuição à ciência matemática. 
realização, seu público mudou drasticamente; não mais existem seu poderoso comitente e poucos fiéis afortunados, mas observadores eruditos e muitos turistas afoitos, eventualmente inventivos e curiosos. A tarefa dos historiadores da arte e da cultura é recuperar a partir de documentos de época parte do contexto de sua realização para que algum entendimento objetivo seja possível, uma tarefa que não raro ocupa toda uma vida.

Segundo Baxandall (1991, p. 38), cada pessoa tem seu estilo cognitivo individual. $\mathrm{Na}$ vida cotidiana, isso é praticamente insignificante, mas "em algumas circunstâncias, a diferença entre um indivíduo e outro, em alguns casos marginais, pode adquirir uma curiosa importância”. Na introdução do livro, um dos autores expressa inocentemente seu estilo cognitivo individual ao descrever sua primeira visita à Sistina, a qual lhe proporcionou a primeira idéia do livro. A respeito do Pecado original, após mencionar a figura feminina que tenta Adão e Eva, ele escreve (1991, p. 20-1):

O que me chamou a atenção, porém, foi o pequeno toco árido com um ramo apontado para cima que está ao lado de Eva. Poucos dias antes, ainda me dedicava a um longo estágio que realizei no Departamento de Anatomia da Universidade. Nele, a prática me havia direcionado para a especialização cirúrgica. Com a mente impregnada dos estudos anatômicos, vi nesse toco um arco aórtico dissecado.

A “curiosa importância” de Baxandall, aqui evidentemente não relacionada a um caso marginal da história da arte, passou ao largo dele e de seu fiel colega durante o único ano de estudos em que eles se dedicaram a descobrir as anatomias secretas de Michelangelo Buonarrotti. Na filosofia da ciência, se aqui é permitida uma expressão do âmbito das chamadas "ciências duras", chama-se isso de "impregnação teórica dos fatos". No cotidiano, pessoas leigas sabem disso ao dizer que "cada pessoa vê o mundo com os olhos que tem", mas elas não levam isso às suas últimas conseqüências, isto é, face a uma situação qualquer cada pessoa só pode conhecer a si mesma. Sem saber disso, elas não sabem a importância e mesmo a necessidade de transcender isso na busca por objetividade, como o livro em questão evidentemente mostra. A impregnação teórica é necessária para a elaboração de hipóteses, mas necessita ser confirmada por critérios intersubjetivos. Concordando com os autores (p. 27), a obra de Michelangelo não foi deixada para leigos.

Por fim, resta indagar a respeito da edição do livro em questão, um livro ricamente ilustrado e de edição evidentemente cara como poucos livros de história da arte lançados no Brasil. Não cabe aqui supor más intenções por parte dos autores, pois seu texto expressa sinceramente a ingenuidade de duas pessoas fascinadas por suas descobertas. Entretanto, apenas sinceridade não faz uma boa obra, qualquer que seja. Pode-se supor a falta de rigor de seus editores. O prefácio repleto de lugares comuns a respeito 
do Renascimento, os quais lembram algum iluminista muito ingênuo e retardatário a maldizer mais uma vez a ainda tão maldita Idade Média, não resiste nem mesmo a mais caridosa das leituras, assim como os elogios presentes na contra-capa do livro, feitos por médicos sem cultura para comentar um livro que, mesmo contendo aspectos da medicina, é um livro de história. Pode-se pensar também a respeito de uma edição de feição comercial voltada a um público pouco exigente, o qual talvez se encante com suas interpretações inventivas e curiosas e com seu jogo de associações livres. Seja como for, mesmo com evidentes pretensões de influir nos estudos acadêmicos a respeito da obra de Michelangelo, o livro em questão não os compromete, pois historiadores não se deixam enganar por sua falta de rigor. Entretanto, o livro é prejudicial à educação de pessoas leigas genuinamente interessadas em se instruir a respeito de história da arte e da cultura do Renascimento em geral, e sua falta de precisão das categorias da época e suas diferenças em relação às categorias atuais, especialmente as relacionadas à ciência, contribui para a ignorância do senso comum relativa à ciência e a métodos rigorosos de investigação históricos, ignorância da qual o livro de Gilson Barreto e Marcelo G. de Oliveira também é vítima.

\section{Eduardo Henrique Peiruque Kickhöfel \\ Membro do Projeto Temático \\ "Estudos de filosofia e história da ciência" da FAPESP, doutorando do Departamento de Filosofia da Universidade de São Paulo. kickhofel@hotmail.com}

\section{REFERÊNGIAS BIBLIOGRÁFIGAS}

Barocchi, P. (Ed.). Scritti d'arte del cinquecento. Milão/Nápoles, Riccardo Ricciardi Editore, 1971. v. 1.

Baxandall, M. O olhar renascente. Pintura e experiência social na Itália da Renascença. Trad. de M. G. P. R. Almeida. São Paulo, Paz e Terra, 1991 [1972].

Bernabeo, R. Artisti pre-vesaliani. In: Ciardi, R. P. \& Tomasi, L. T. (Ed.). Immagini anatomiche e naturalistiche nei disegni degli Uffizi, secc. XVI XVII. Florença, Gabineto Disegni e Stampe degli Uffizi LX/Leo S. Olschki Editore, 1984. p. 31-6.

Brizio, A. M. The painter. In: Reti, L. (Ed.). The unknown Leonardo. Nova Iorque, Abradale Press/Harry N. Abrams Publishers, 1974. p. 20-55.

Chastel, A. Treatise on painting. In: Reti, L. (Ed.). The unknown Leonardo. Nova Iorque, Abradale Press/ Harry N. Abrams Publishers, 1974. p. 216-39.

Ciardi, R. P. \& Tomasi, L. T. (Ed.). Immagini anatomiche e naturalistiche nei disegni degli Uffizi, secc. XVIe XVII. Florença, Gabineto Disegni e Stampe degli Uffizi LX/Leo S. Olschki Editore, 1984. 
UMA FALSA LIÇÃO DE ANATOMIA...

Condivi, A. Michelangelo: la vita raccolta dal suo discepolo Ascanio Condivi. Milão, P. d’Ancona, 1982.

Galluzzi, P. Renaissance engineers from Brunelleschi to Leonardo. Florença, Giunti, 1996.

Jaeger, W. Paideia. A formação do homem grego. Trad. de A. M. Parreira. São Paulo, Martins Fontes, 1979 [1936].

Kristeller, P. O. Humanism. In: Schmitt, G. B.; Skinner, Q. \& Kessler, E. (Ed.). The Cambridge history of Renaissance philosophy. Cambridge, Cambridge University Press, 1988. p. 113-37.

Panofsky, E. Idea. Ein Beitrag zur Begriffsgeschichte der älteren Kunsttheorie. Leipzig, Teubner, 1924. (Studien der Bibliothek Warburg V).

Artist, scientist, genius: notes on the "Renaissance-Dämmerung". In: The Renaissance. Six essays. Nova Iorque, Harper \& Row Publishers, 1962. p. 121-82.

Perrig, A. Michelangelo's drawings. Yale, Yale University Press, 1991.

Reti, L. (Ed.). The unknown Leonardo. Nova Iorque, Abradale Press/Harry N. Abrams Publishers, 1974.

Schlosser, J. La letteratura artistica. Florença/Viena, La Nuova Italia/Kunstverlag Anton Schroll, 1994 [1924].

Schmitt, G. B.; Skinner, Q. \& Kessler, E. (Ed.). The Cambridge history of Renaissance philosophy. Cambridge, Cambridge University Press, 1988.

Singer, C. A study in early Renaissance anatomy, with a new text. The Anathomia of Hieronymo Manfredi (1490). In: (Ed.). Studies in the history and method of science. Nova Iorque, Arno Press, 1975. v. 1. p. $80-164$.

Tonlay, C. de. Corpus dei disegni di Michelangelo. Novara, Istituto Geografico de Agostini, 1975. v. 1.

VASARI, G. Le vite de' piu' eccellenti pittori, scultori e architettori scritte da Giorgio Vasari pittore a architetto aretino. Florença, Presso S. Audin, 1822 [1568]. v. 3.

Wallace, W. A. Traditional natural philosophy. In: Schmitt, G. B.; Skinner, Q. \& Kessler, E. (Ed.). The Cambridge history of Renaissance philosophy. Cambridge, Cambridge University Press, 1988. p. 201-35.

White, M. Leonardo, o primeiro cientista. Rio de Janeiro, Record, 2002 [2000]. 